\title{
A Novel Animal Model of Hippocampal Cognitive Deficits, Slow Neurodegeneration, and Neuroregeneration
}

\author{
Simon C. Spanswick, ${ }^{1}$ Hugo Lehmann, ${ }^{2}$ and Robert J. Sutherland ${ }^{3}$ \\ ${ }^{1}$ Department of Psychology, University of Calgary, 2500 University Drive NW, Calgary, AB, Canada T2N 1N4 \\ ${ }^{2}$ Department of Psychology, Trent University, 1600 West Bank Drive, Peterborough, ON, Canada K9J 7B8 \\ ${ }^{3}$ Department of Neuroscience, University of Lethbridge, 4401 University Drive, Lethbridge, AB, Canada T1K 3M4
}

Correspondence should be addressed to Simon C. Spanswick, simon.spanswick@uleth.ca

Received 16 September 2010; Accepted 19 January 2011

Academic Editor: Oreste Gualillo

Copyright (c) 2011 Simon C. Spanswick et al. This is an open access article distributed under the Creative Commons Attribution License, which permits unrestricted use, distribution, and reproduction in any medium, provided the original work is properly cited.

Long-term adrenalectomy $(\mathrm{ADX})$ results in an extensive and specific loss of dentate gyrus granule cells in the hippocampus of adult rats. This loss of granule cells extends over a period of weeks to months and ultimately results in cognitive deficits revealed in a number of tasks that depend on intact hippocampal function. The gradual nature of ADX-induced cell death and the ensuing deficits in cognition resemble in some important respects a variety of pathological conditions in humans. Here, we characterize behavioural and cellular processes, including adult neurogenesis, in the rat ADX model. We also provide experimental evidence for a neurogenic treatment strategy by which the lost hippocampal cells may be replaced, with the goal of functional recovery in mind.

\section{Introduction}

Animal models are widely and successfully used to reproduce important aspects of pathologies associated with brain disorders in many areas of neuroscience. Even within a single neuropathological condition, there exists a wide diversity of models, each attempting to delineate a specific cause and/or potential treatment strategy for the condition in question. Here, we present a novel animal model that has several favourable features that allow for examination of whether neuronal replacement in the hippocampus can reverse memory deficits caused by selective degeneration of hippocampal neurons. Characterization of regenerative success in our simple model system should provide fundamental information about the required conditions for replacing neural circuitry in other brain regions more generally and ultimately should support a treatment strategy for disorders involving neuronal loss.

The hippocampus, a key region of the medial temporal lobe, is a frequent target in many neurological diseases and most forms of dementia. It is well established that the hippocampus can degenerate in Alzheimer's disease [1], posttraumatic stress disorder [2], Parkinson's disease [3], epilepsy [4], and following acute trauma such as hypoxia and stroke [5], to mention only a few conditions. It is also clear that damage to the hippocampus accounts for many of the cognitive deficits observed in these diseases, particularly those concerned with long-term memory.

In animal models of hippocampal neuronal loss, there is benefit from employing existing strategies for restoring functions. In none of the models, however, there is good evidence that lost cells are replaced and that the new cells take up normal positions in respect to connectivity. The grafting strategy attempts to replace lost tissue by placing donor embryonic or stem cells directly into the target region. In general, these approaches have success that is clearly limited $[6,7]$. In hippocampus, there is survival of a significant number of grafted cells, some evidence for integration into local circuitry, and at least partial reversal of some behavioural deficits. There is an increase in extracellular transmitter, which likely overcomes some of the deficits, but it is extremely unlikely, despite some synaptogenesis, that these transplanted cells have established correct pre- and postsynaptic connections that normalize information processing by the hippocampal network. Even in instances of excellent graft survival with multiple transplant 
locations, there are clear persisting functional deficits [8-10]. It seems that normal information processing does not take place in hippocampal grafts $[8,11]$. There is some recent evidence that grafts of embryonic CA3 tissue promote expression of calbindin in existing hippocampal neurons after CA3 excitotoxic injury, and this might be beneficial for hippocampal excitability [12]. Furthermore, embryonic neuroblasts implanted into normal or pilocarpine-damaged hippocampal rats survive, establish some connections with the host, but remain in clumps, not likely restoring normal information processing [13]. Thus, regardless of approach, the objective of repairing damaged HPC circuits still seems to be beyond our reach.

A new set of opportunities has opened up based upon the surprising discovery that in the adult brain, there are at least two pools of cells that continuously generate new neurons. One of these pools of neurogenic stem cells is centered on the subventricular zone of the lateral ventricular wall, and the other, a focus of our work, is located in the dentate subgranular zone of the hippocampus. This process of adult neurogenesis is known to occur in the hippocampus of adult humans [14]. Thus, our novel, and we believe promising, animal model involves upregulating hippocampal neurogenesis in order to repair the damaged circuitry and reverse associated cognitive impairments. Therefore, a major advantage of our model is that the restoration of damaged circuitry occurs through manipulating an endogenous process.

Thus, our animal model capitalizes on two strange properties of the hippocampus. First, hippocampal granule cells slowly and selectively die after CORT is completely eliminated. Second, uniquely in the cortex, in adults, there is a steady addition of newborn granule cells to the hippocampal network. Below, we describe and explain the experimental manipulation that produces a gradual and targeted loss of granule cells in the dentate gyrus subfield of the hippocampus of adult rats. Specifically, we show histological findings that outline the time course and extent of this cell loss. Next, we present evidence for the effects of this cell loss on the electrophysiological properties of the dentate gyrus and characterize its ensuing impact on behaviour. Finally, we present a treatment strategy that takes advantage of adult dentate gyrus neurogenesis; precisely, that upregulation of adult neurogenesis results in a significant repopulation of the dentate gyrus granule cell layer.

\section{Experimentally-Induced Granule Cell Loss in the Adult Dentate Gyrus}

Our animal model utilizes ADX to induce a gradual and specific loss of granule cells within the adult rat dentate gyrus. Robert Sloviter and colleagues first reported the loss of granule cells in the dentate gyrus resulting from ADX in 1989 [15]. They observed a selective loss of dentate gyrus granule cells in the hippocampus, three-to-four months after ADX in adult rats. Importantly, using immunohistochemical and electrophysiological techniques, Sloviter et al. $[15,16]$ showed that other hippocampal subfields were essentially unaffected by ADX, demonstrating the specificity of cell loss after ADX. Moreover, CORT replacement immediately after ADX prevented cell loss from the granule cell layer. These findings suggest that the absence of CORT associated with ADX causes specific degeneration within the dentate gyrus while sparing other hippocampal regions.

Work by Gould et al. [17] confirmed the specificity of ADX-induced cell loss, showing the presence of pyknotic cells in the hippocampal granule cell layer (but not CA1 or CA3) of rats, three days after ADX. Subsequent investigation by Woolley et al. [18] demonstrated that specific activation of type 1 adrenal steroid receptors via aldosterone is also sufficient to prevent the loss of dentate gyrus granule cells associated with ADX, providing identification of an initial trigger of the mechanism by which post-ADX granule cell death occurs. Woolley et al. [18] also confirmed the specificity of cell death in the rat hippocampus, noting a significant increase in pyknotic cells in the granule cell layer of the dentate gyrus seven days after ADX. Using electron microscopy, Sloviter et al. [16] provided further evidence for apoptotic cell death in the dentate gyrus granule cell layer as a result of ADX. They reported a number of morphological changes in dentate granule cells that are characteristic of apoptosis (condensed nuclear chromatin, compaction of cytoplasm, blebbing). Other markers of cell death have been employed to characterize granule cell loss after ADX, including silver impregnation $[19,20]$, caspase-9 [21], and terminal dUTP nick end labeling (TUNEL, [22]).

Although the aforementioned studies demonstrated ADX-induced neural degeneration, none has provided a time course of the degeneration or described its progression. Using the cell death marker Fluoro-Jade B [23], we examined both the onset and time course of hippocampal granule cell death after ADX. Specifically, Fluoro-Jade B expression within the dentate gyrus was assessed in rats that were sacrificed 1-7 days and 2, 4, 8, or 23 weeks after ADX. We found that as described previously $[17,19]$, cell death is evident by three days after complete removal of circulating CORT. Very little, if any, Fluoro-Jade positive cells were detected in rats sacrificed 1 or 2 days after ADX, yet consistent labeling was observed in the rats that were sacrificed 3 or more days after. Furthermore, granule cell death increased steadily from one to two weeks, peaking at the fourth week and remained high in week eight. Moreover, cell death could still be observed 23 weeks after ADX, but not to the same extent as in the previous time point. Thus, for a period of up to at least 23 weeks, a large pool of granule cells die as a result of ADXinduced CORT depletion (Figure 1).

The continuing loss of hippocampal granule cells in the adult rat is a nice feature of this model, as it resembles slow neurodegenerative processes of neuronal loss experienced by individuals suffering from various forms of dementia [24], delayed hippocampal neuronal loss associated with stroke [25], as well as traumatic brain injury [26]. The relatively slow loss of neurons as a result of ADX is also congruent with many other neurodegenerative disorders including Huntington's [27] and Parkinson's disease [28].

The gradual loss of granule cells associated with chronic ADX can lead to substantial damage in the dentate gyrus. After 10 weeks of ADX we have found that approximately 


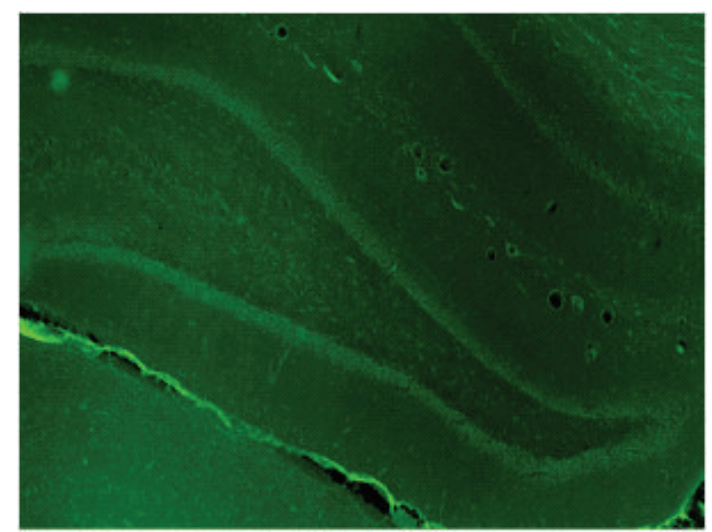

(a)

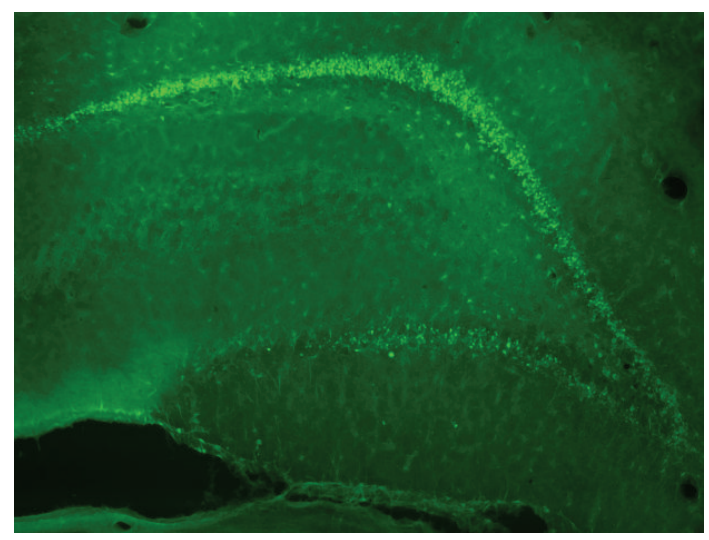

(c)

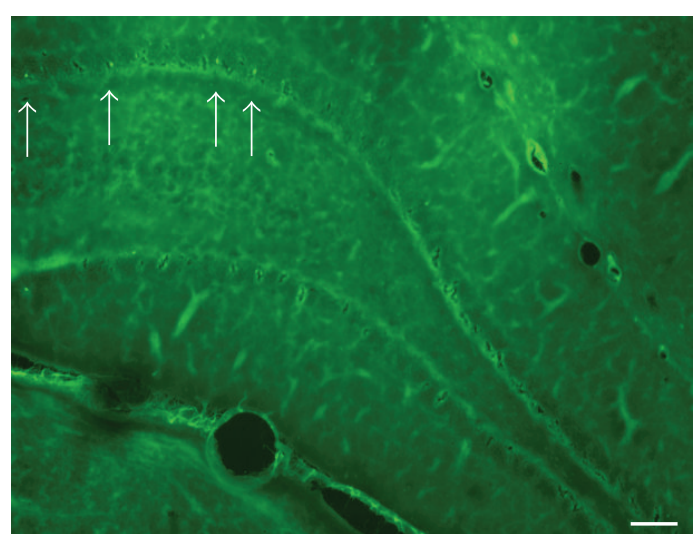

(b)

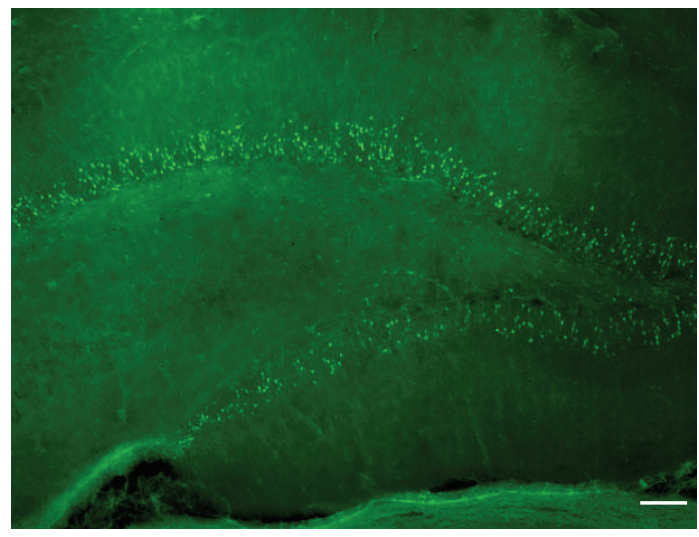

(d)

Figure 1: Representative Fluoro-Jade B labeled sections taken from a control (a) and adrenalectomized (ADX) rats at 3 days (b), 8 weeks (c), and 23 weeks (d) after surgery. No Fluoro-Jade B positive cells were apparent in control tissue (a). Fluoro-Jade B positive cells were evident by 3 days after ADX (indicated by arrows) and appeared in the superior lateral blade of the dentate gyrus (b). At 8 weeks after ADX surgery, Fluoro-Jade B positive cells were evident throughout the entire granule cell layer but was still most concentrated in the superior, lateral blade (c). Fluoro-Jade B labeling has substantially decreased at the 23-week time point but was still apparent throughout the entire dentate gyrus granule cell layer $(\mathrm{d})$. Scale bar $=100 \mu \mathrm{m}$.

25 percent of the volume of the granule cell layer is lost (Figure 2(c); [29]). These estimates were obtained by quantifying granule cell layer volume using the Cavalieri volume estimator [30-33]. This technique allows for a relatively quick and easy estimate of ADX-induced damage in the dentate gyrus. A more refined estimate, however, can be obtained by quantifying the total number of remaining cells after ADX using the optical fractionator technique. The latter revealed that 10 weeks of ADX-induced cell death caused approximately a 50 percent reduction in dentate gyrus granule cells (Figure 2(d); [29]). Not surprisingly, there is a strong and significant correlation between volume and total granule cell number in the dentate gyrus, suggesting that the decrease in volume after ADX is at least in part due to the loss of granule cells. Our findings are congruent with previous studies showing granule cell loss in the dentate gyrus after long-term ADX [15, 34-36]. However, we advocate that the estimates that we present here are more accurate, as they relied on unbiased stereological approaches.

In summary, ADX and its resulting CORT depletion causes prolonged cell death that is restricted to the granule cell layer of the dentate gyrus. A 10-week degeneration period results in noticeable damage in the dentate gyrus that can easily be quantified stereologically. As such, we have a slow neurodegeneration model that limits its damage to an area of the brain known for critical cognitive function, particularly memory. A fundamental question now arises: what are the in vivo effects of the selective degeneration of hippocampal granule cells? We examined this question by investigating the electrophysiological properties of the dentate gyrus following ADX-induced degeneration and more importantly its ensuing impact on behavior.

\section{In Vivo Implications of Hippocampal Granule Cell Loss}

To determine the functional effects of granule cell death in vivo, we utilized a battery of electrophysiological and behavioural indices. Specifically, we performed input/output (I/O) curves on awake, freely behaving ADX rats and recorded population spike amplitude and field excitatory 


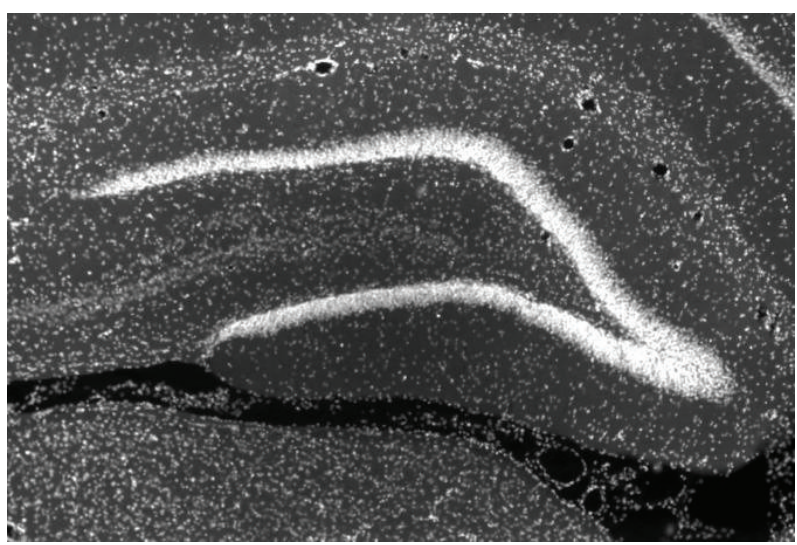

(a)

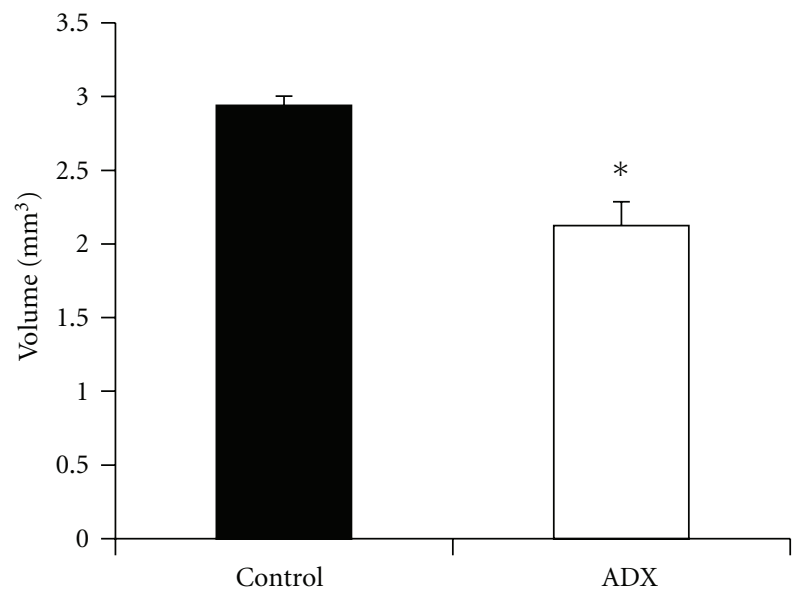

(c)

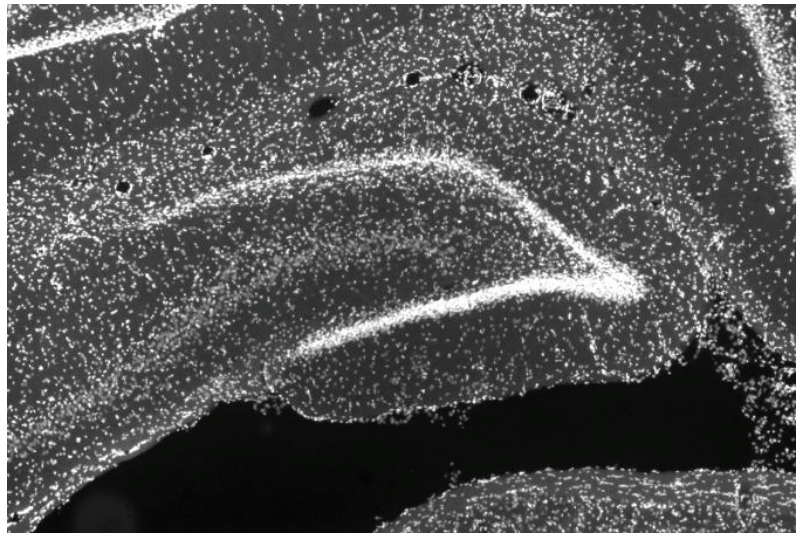

(b)

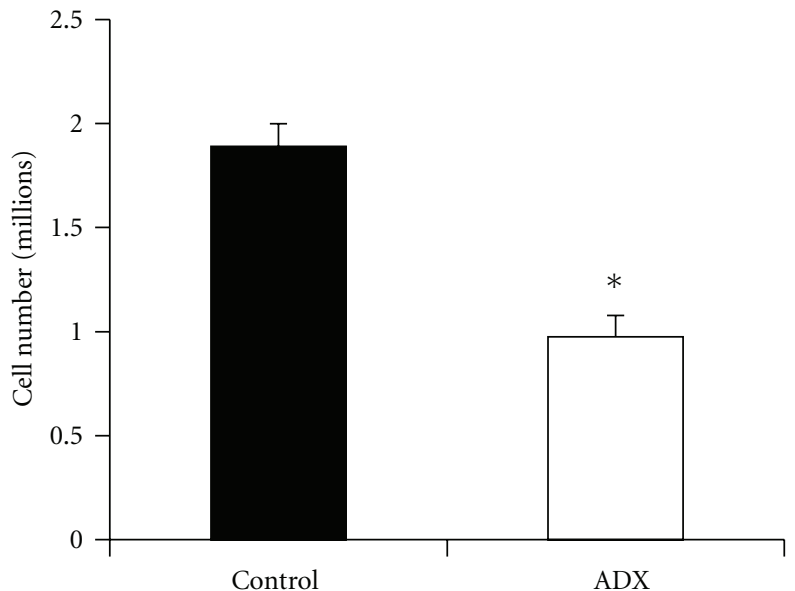

(d)

FIGURE 2: Representative DAPI-labeled sections containing the dentate gyrus granule cell layer in a control (a) and an adrenalectomy (ADX) rat (b) after 10 weeks of degeneration. (c) By 10 weeks, ADX rats had lost approximately one-third of the volume of the dentate gyrus granule cell layer when compared to adrenally intact controls. (d) Cell counts using the optical fractionator revealed a loss of roughly half of the dentate gyrus granule cells at the same time point. * indicates significant difference; error bars represent standard error of the mean (adapted from [29]).

post synaptic potentials (fEPSPs). In addition, we used several behavioural tests (Morris water task, object/context mismatch, and open field activity) to assess the effect of hippocampal granule cell loss on behaviour and cognition.

Our animal model requires that after the 10-week degeneration period, rats are provided with replacement CORT. The administration of CORT serves two purposes: (1) it prevents further ADX-induced apoptosis and (2) allows us to determine the functional deficits strictly associated with the loss of granule cells and not the effects of CORT depletion per se. Indeed, any changes observed following ADX could be due to complete removal of circulating CORT and/or the ensuing loss of dentate gyrus granule cells. By administering CORT, we mitigate the potential adverse effects of the hormone depletion and can more accurately assess the effects of granule cell degeneration specifically. Thus, we administer a daily, oral dosage of CORT (1 mg), after the 10 -week degeneration period and throughout the remainder of our studies. This method of CORT replacement has been demonstrated as effective at inducing a diurnal rhythm in
ADX rats that is similar to intact controls [36] and in preventing ADX-induced cell death [15], electrophysiology alterations [37], and behavioural deficits [34].

With the exception of the report by Sloviter et al. [15], much like post-ADX reports of cell death [17, 20], electrophysiological studies have been performed at time points very soon after surgery. A number of experiments have reported alterations in granule cell electrophysiology, usually ranging from 3 [37-39] to 10 days [40] after ADX. The short time course of these experiments means that little is known about the effects of chronic ADX and the associated gradual loss of hippocampal granule cells on the electrophysiological properties of the dentate gyrus. Pilot data collected from our laboratory shows that 10 weeks of ADX-induced dentate gyrus granule cell layer degeneration is sufficient to produce deficits in electrophysiological function despite rats receiving replacement CORT at the time of measurement. I/O curves were performed on awake, freely behaving control, and ADX rats, and population spike amplitude and fEPSPs were recorded. We found a marked attenuation of the 
electrophysiological response of the dentate gyrus in chronic ADX rats. Specifically, we noticed a significantly lower fEPSP slope and a decreased population spike in ADX rats after 10 weeks of granule cell layer degeneration when compared to intact controls (Figure 3). Importantly, all ADX rats received replacement CORT starting one week prior to and during the time of data collection. Thus, 10 weeks of cell death, that typically leads to a 50\% decrease in cells in the granule cell layer of the dentate gyrus, cause substantial electrophysiological disturbances within the hippocampus.

Pivotal to our model, the ADX-induced degeneration in the dentate gyrus leads to significant behavioural changes and cognitive deficits. More specifically, the loss of granule cells due to long-term ADX results in cognitive deficits in at least two tasks that have been shown to depend on intact hippocampal function. Using a moving platform version of the Morris water task, we demonstrated that rats with dentate gyrus damage performed poorly relative to controls [36], replicating prior research that suggests damage focused on the dentate gyrus (including ADX) produces deficits in spatial tasks [34, 41-43]. Using a novel/familiar platform location paradigm, we were able to assess both memory acquisition and 24-hour retention. We found that ADX rats take longer to locate a hidden platform within the Morris water task, regardless of whether it was in a familiar or novel location (Figure 4(a)). This significant increase in time to find the platform is not explained by differences in swim speed between ADX and intact control animals. Of note is that during our investigation, all of our ADX rats received replacement CORT and still presented with spatial deficits. This finding adds to a body of evidence that suggests a loss of granule cells is sufficient to produce cognitive deficits.

We have also reported behavioural deficits following 10 weeks of ADX-induced cell degeneration in a spontaneous recognition task [29]. Prior investigation has shown that rats with damage limited to the hippocampus perform novel object preference tasks at levels similar to controls but display deficits when information about context [44] or place [45] becomes important for successful recognition. Thus, we tested the ability of rats to recognize whether an object is associated with the context in which it was originally encountered. Rats are presented with a pair of identical objects in one context (Context A), and after a short exploration period, they are presented with another pair in an alternate context (Context B). During this acquisition phase, rats are provided with equal exposure to the two object pairs, each pair housed in a different context. For the test, rats are returned to either of the contexts (A or B), but now, an object from each pair is present. Normally, rats will spend a greater proportion of their object investigation time with the mismatched object (i.e., the one never encountered in that context before). We term this spontaneous recognition task the object/context mismatch task. ADX animals perform significantly worse than controls on this task and fail to show preferential investigation of the object that is mismatched (Figure 4(b)).

The deficits we observe in rats after long-term ADX bear a family resemblance to those experienced by people displaying a loss of hippocampal function [46-49]. Spatial

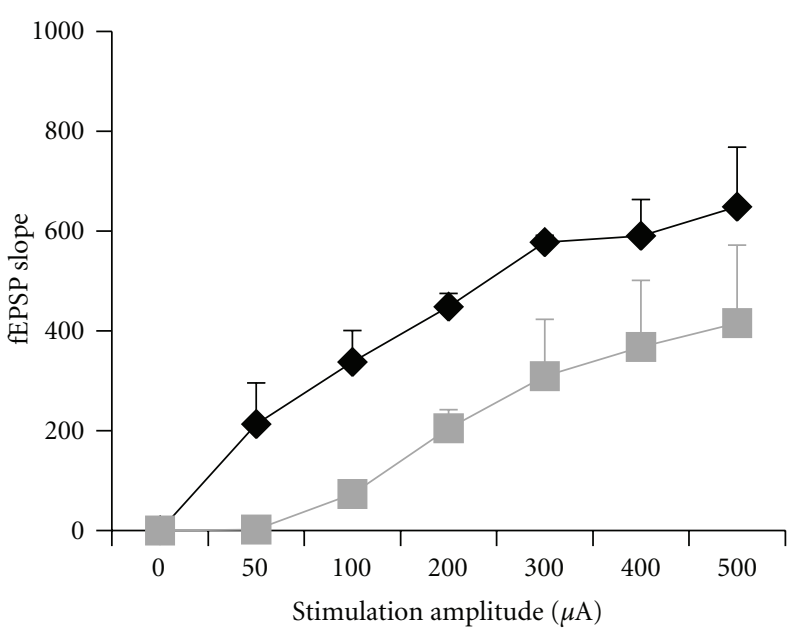

(a)

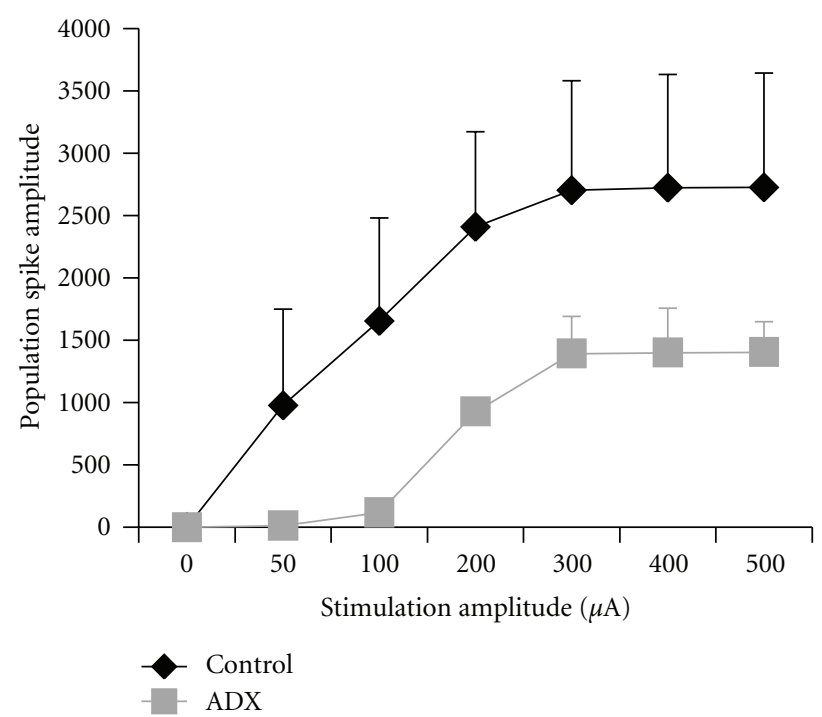

(b)

Figure 3: Pilot data assessing the electrophysiological response of the dentate gyrus after 10 weeks of adrenalectomy (ADX) followed by one-week of CORT replacement, all ADX rats were on CORT replacement at the time of recording. (a) Chronic ADX resulted in a significantly attenuated fEPSP slope relative to control rats. (b) A tendency for ADX rats to have a lower population spike amplitude compared to intact controls was apparent. Error bars represent standard error of the mean.

deficits as a result of hippocampal atrophy due to Alzheimer's disease [50] and hippocampal damage associated with surgical resection [47] have been reported in the virtual Morris water task, the human analogue of the spatial task we employed to assess behaviour in our ADX animals [36]. Astur et al. [47] show that human patients with surgeryinduced unilateral hippocampal damage took significantly longer to locate a hidden platform and spent less time "swimming" in the correct quadrant during a probe trial in the virtual Morris water task than their age-matched cohorts. The disruption in recognition memory by altering the context in which objects are presented has also been 


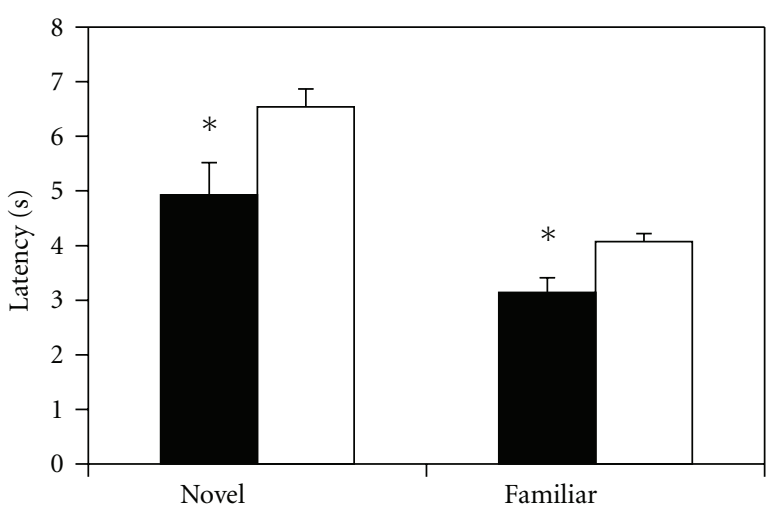

Control $\square \operatorname{ADX}$

(a)

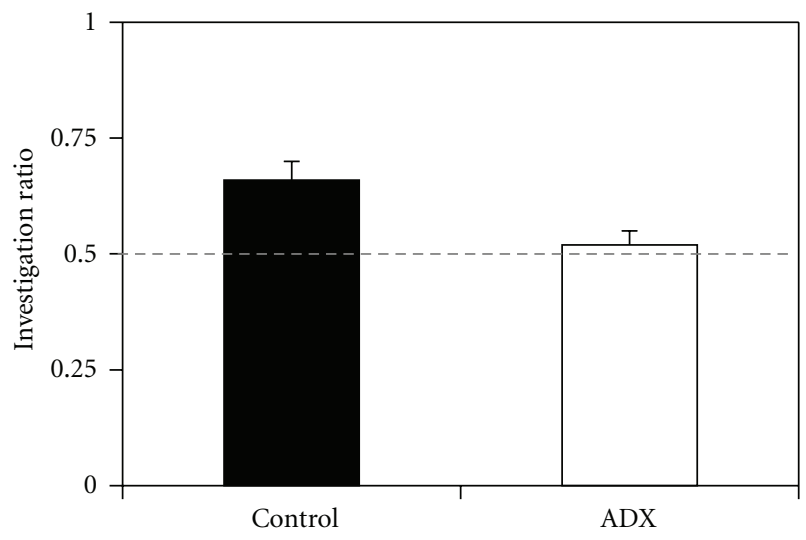

(b)

FIGURE 4: Behavioural deficits associated with long-term ADX. (a) ADX rats were impaired relative to controls at locating both novel and familiar platform locations in a moving platform version of the Morris water task. (b) Discrimination ability of ADX rats in the object/context mismatch task was significantly impaired. ADX rats did not discriminate above chance levels. Dashed lines represent chance, error bars represent standard error of the mean.

observed in human patients suffering from hippocampal damage [49], a finding that is congruent with our data, showing diminished novel object/context association in ADX rats [29]. Pascalis and colleagues [49] show that when the context in which an object is first presented (familiarization) and subsequently reintroduced (test) is changed, patients with hippocampal damage show a lack of object preference, despite intact object recognition when the background context remained constant.

\section{Adult Hippocampal Neurogenesis: A Potential Treatment Strategy}

It is well established that the birth of new neurons in the brain continues throughout all of adulthood. The processes of proliferation, migration, and integration of new neurons in the adult brain are now well-described phenomena, both in the dentate gyrus [51] and the subventricular zone [52]. Numerous modulators of the neurogenic process within the adult hippocampus have been discovered, ranging from the administration of pharmacological agents such as fluoxetine [53, 54], growth factors [55], exercise [56, 57], environmental enrichment $[56,58]$, to stress and stress hormones [59-61].

ADX itself has been demonstrated to alter neurogenesis. Gould and colleagues [59] reported an increase in proliferation six days after ADX as determined by an increase in the density of tritiated thymidine-labeled cells in the dentate gyrus of ADX rats compared to controls. Further studies have confirmed this phenomenon, finding increases in proliferation within the dentate gyrus at time points ranging from six to twelve days after $\operatorname{ADX}[60,62,63]$.

All of the aforementioned studies assessing proliferation after ADX have done so without CORT replacement [59, $60,62,63]$. These studies demonstrate that proliferation continues in the adult dentate gyrus in the absence of CORT, at least at relatively short time points after ADX. It is well documented that adult born granule cells mature into functional units within the dentate gyrus [51], eventually becoming indistinguishable from their surrounding counterparts. As ADX eliminates mature dentate gyrus granule cells [15] it is not unreasonable to conclude that CORT is necessary to ensure the survival of adult-born granule cells. Our CORT replacement strategy not only serves to prevent further granule cell layer degeneration but also ensures the survival of those hippocampal granule cells born in the adult ADX rat.

Our animal model utilizes the phenomenon of adult neurogenesis in an attempt to repopulate the damaged dentate gyrus with adult-born granule cells. As such, it is necessary to demonstrate that neurogenesis continues in the damaged dentate gyrus and that it can be upregulated to a level sufficient to significantly replace lost neurons within the adult hippocampus. We have previously shown that neurogenesis continues in the ADX brain at levels similar to adrenally intact controls [36]. Specifically, we report that the number of proliferating cells (as determined by Ki67 expression) and migrating neuroblasts (those cells expressing the microtubule-associated protein doublecortin (DCX)) does not differ significantly between chronic ADX and control rats. This is important because it shows that despite significant degeneration of the granule cell layer, the subgranular zone remains viable.

Indirect evidence from our 2007 study [36] suggested that the treatment strategy we had employed (eight weeks of daily fluoxetine administration) transiently increased hippocampal neurogenesis. Despite a lack of a significant difference in neurogenesis between ADX rats and controls, there was a tendency for ADX rats that were treated with fluoxetine to have a thicker dentate gyrus than those that were untreated. This suggests that fluoxetine may have induced a transient increase in neurogenesis, resulting in a thicker granule cell layer. These results prompted us to examine other neurogenic treatment strategies. 


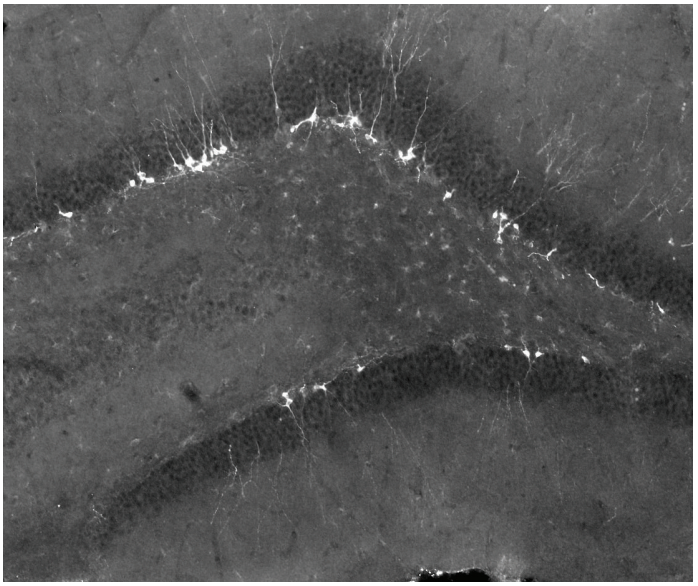

(a)

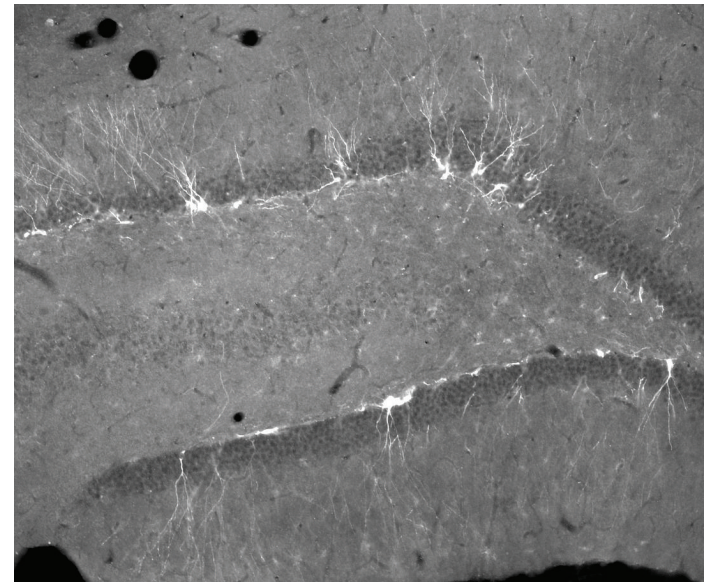

(c)

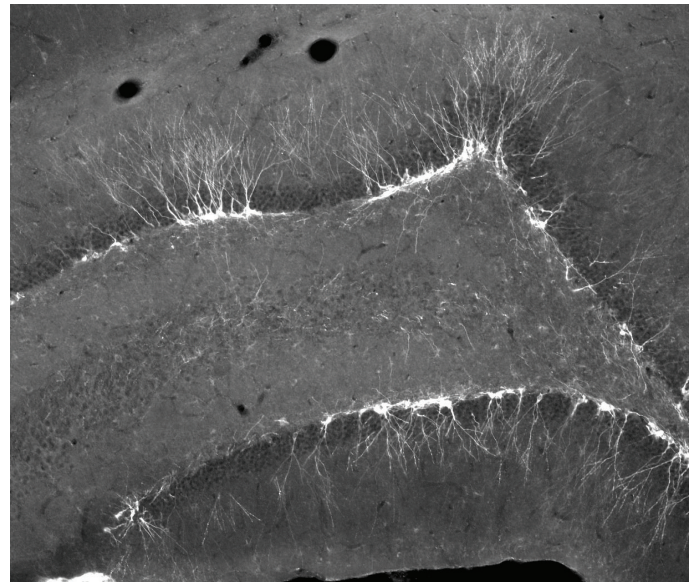

(b)

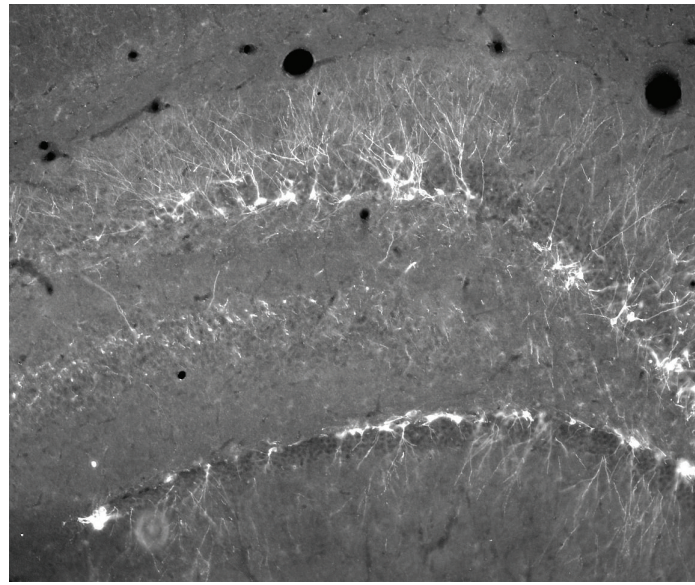

(d)

FIgURE 5: Regardless of adrenalectomy (ADX), the combined enrichment and exercise treatment significantly increased neurogenesis as indexed by doublecortin (DCX). Representative pictures of DCX positive cells in the dentate gyrus of (a) home cage controls, (b) controls exposed to wheel running and enrichment, (c) ADX rats housed in the home cage, and (d) ADX rats exposed to wheel running and enrichment.

We succeeded in substantially repopulating the dentate gyrus following 10 weeks of ADX-induced degeneration by using a unique combination of enriched housing and wheel running. Specifically, we housed our rats in a $24-$ hour alternating condition of group-housed environmental enrichment and individual access to a running wheel over a period of 6 weeks. It is believed that the effects of exercise and environmental enrichment on adult neurogenesis are dissociable [57]. Exercise (in the form of wheel running) has been shown to increase the proliferation of new cells, specifically targeting Type-2 cells [51, 57]. Environmental enrichment can dramatically increase the number of new dentate gyrus granule cells but may not increase proliferation. Enrichment may primarily increase the proportion of progenitors that are selected to survive to granule cell maturity $[57,64]$.

The proliferation of hippocampal granule cells occurs in the ADX rat (with or without replacement CORT), even at long time points. Despite this, ADX rats present with behavioural deficits in a multitude of tasks. This suggests that it is the mature granule cells are critical for certain behaviours. Simply increasing the proliferation of new cells is, therefore, unlikely to ameliorate the deficits associated with ADX. Rather it is the survival and functional integration of these cells that is key. Our combination of wheel running and enriched housing was selected to maximize the possibility that new cells in the damaged dentate would survive to a functional endpoint.

We found that a significantly greater number of DCX positive cells were evident in ADX rats that received the enriched environment and wheel running (Figures 5 and 6(a)) compared to those remaining in the home cage. This is consistent with extensive evidence suggesting that neurogenesis can be increased by enriched environmental housing $[56,58,65]$ and exercise $[66,67]$. Importantly, the number of DCX positive cells present in ADX rats is similar to that which is observed in controls. Despite the significant depletion of granule cells in the dentate gyrus caused by ADX, hippocampal neurogenesis continues, providing further evidence that the subgranular zone remains viable after long-term ADX. 


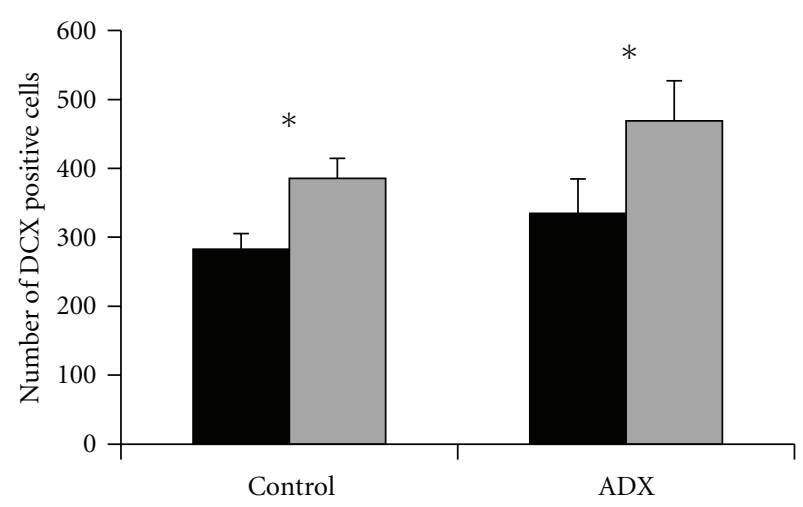

(a)

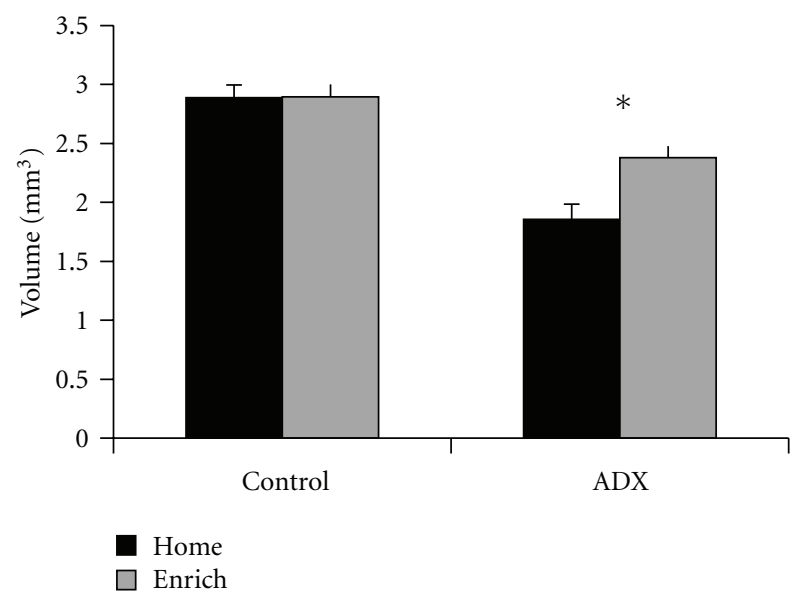

(b)

Figure 6: (a) Our alternating treatment of enrichment and wheel running significantly increased the number of doublecortin (DCX) positive cells in the dentate gyrus of adrenalectomy (ADX) and control rats. (b) Chronic ADX significantly reduced the volume of the dentate gyrus granule cell layer. Most importantly, a combination of six weeks of enriched housing significantly increased the volume of the dentate gyrus granule cell layer in ADX rats, compared to their home cage counterparts. Error bars represent standard error of the mean.

The most exciting finding, however, is that a combination of six weeks of environmental enrichment and wheel running increased the volume of the granule cell layer in ADX rats compared to those that remained in the home cage (Figure 6). Hence, enhancing neurogenesis was successful in at least partially repopulating a damaged dentate gyrus in adult animals. The significantly higher levels of DCX in rats that received the enrichment/exercise treatment show that earlier stages of neurogenesis had indeed been upregulated. The increase in volume of the dentate gyrus in ADX rats that experienced enrichment and exercise, a measure strongly correlated with granule cell number [29], suggests that the survival of adult born granule cells was also increased.

Although the volume of the hippocampal granule cell layer in treated ADX rats did not reach control levels, the significant repopulation of cells suggests that treatments that upregulate adult neurogenesis may provide an effective strategy by which lost function may be restored. The high levels of DCX present in treated ADX rats at the time of perfusion indicate that simply increasing the treatment period may be sufficient to completely repopulate the damaged dentate gyrus. Taken at face value, our results differ from Naylor et al. [68] who report a transient increase in proliferation as a result of voluntary wheel running at nine, but not 24 days in rats. Kempermann and Gage [69] also demonstrated that short-term but not long-term exposure to an enriched environment increased proliferation in mice, suggesting a similar transient phenomenon. By interleaving enrichment with exercise, we may have extended the duration of the associated increase in proliferation. An alternate possibility is that switching between wheel running and a relatively novel, enriched environment every 24 hours may maintain a degree of novelty that has been suggested as responsible for increases in neurogenesis [69]. Importantly, the animal model we describe provides an excellent method by which to test treatment strategies targeting restoration of function after neuronal loss.

Preliminary evidence from our laboratory suggests that regeneration of the dentate gyrus granule cell layer via adult neurogenesis can restore impaired behaviour [70]. After 10 weeks of granule cell layer degeneration due to ADX, rats were placed on CORT and administered a cocktail of growth factors (FGF-2 and sonic hedgehog) via an osmotic minipump for six weeks in an attempt to increase neurogenesis within the hippocampus. Both FGF-2 [55, 71] and sonic hedgehog $[72,73]$ have been shown to increase neurogenesis in normal animals, specifically targeting early stages of the neurogenic process. During administration of growth factors, ADX rats were group housed in an enriched environment, which has been shown to increase survival of adult born neurons in normal animals [56, 57]. ADX rats that received the neurogenic treatments presented with a greater hippocampal granule cell-layer volume compared to home cage housed ADX rats given vehicle. Furthermore, the volume of the hippocampal granule cell layer in treated ADX rats did not differ from that of controls, indicating, at least by this measure, a complete regrowth of the previously degenerated hippocampal subfield. Importantly, those ADX rats that had an increased dentate gyrus granule cell-layer volume as a result of treatment with an enriched environment, FGF-2, and sonic hedgehog performed significantly better that their ADX cohorts receiving vehicle and did not differ from controls in a contextual discrimination task. This initial finding suggests a functional repopulation of the dentate gyrus granule cell layer in the adult animal, something that has not been reported before. Although more work is required to confirm the results, this compelling finding suggests that functional recovery in the adult animal is a distinct possibility.

\section{General Discussion}

Our animal model utilizes ADX to induce a progressive and specific loss of hippocampal granule cells followed by an upregulated neurogenic period to repopulate the damaged circuitry. To recap the essential features of the model, rats 


\begin{tabular}{|c|c|c|c|}
\hline Procedure & $0-1$ & Week $_{10-16}$ & \multirow[t]{2}{*}{$16-18$} \\
\hline Surgery & & & \\
\hline Degeneration period & & & \\
\hline Treatment period & & & \\
\hline Assessment battery & & & \\
\hline Perfusion & & & \\
\hline
\end{tabular}

FIgURE 7: The experimental time course. Bilateral adrenalectomy (ADX) is conducted at the onset of the experiment. The granule cell layer of the dentate gryus degenerates significantly over the following ten weeks, during which rats remain in their homecages. A subset of ADX rats are exposed to a number of different treatment strategies, after which behavioural and electrophysiological measures can be taken. Upon completion of the experiment, rats are perfused and the granule cell layer is assessed using immunohistochemistry and unbiased stereological techniques.

first undergo ADX surgery and remain in their home cages for at least a 10-week degeneration period. The absence of CORT associated with the removal of the adrenal glands leads to progressive degeneration, producing a $50 \%$ cell loss within the dentate gyrus granule cell layer after 10 weeks. Second, the ADX rats are placed on daily CORT replacement to prevent further degeneration and allow new neurons to establish themselves within the damaged circuitry. In addition, a subset of ADX rats is then exposed to neurogenic treatments in order to increase the endogenous levels of neurogenesis within the adult hippocampus. Third, after the treatment period, rats are subjected to a battery of behavioural tasks and electrophysiological measures designed to evaluate hippocampal function. Finally, the rats are perfused and the hippocampal granule cell layer is assessed using immunohistochemistry and stereological methods. The steps of the model are illustrated in Figure 7.

The described animal model produces a specific and gradual degeneration of neurons within the adult hippocampus. The gradual loss of hippocampal neurons is a hallmark symptom of a number of pathological states, including traumatic brain injury [74-76], stroke [25, 77], and a number of dementias $[24,46]$. Similar to patients that suffer hippocampal atrophy due to prolonged cell loss we show that rats with a long-term loss of hippocampal granule cells suffer from cognitive deficits in tasks that have been shown to depend upon intact hippocampal function.

Of note is that even after a significant degeneration of the granule cell layer, the stem cell niche within the subgranular zone remains a viable substrate for the birth of new neurons in the adult. We are the first to show that dentate gyrus neurogenesis continues at normal levels after chronic (longer than 10 days) ADX in the adult rat. We are also the first to show that at much longer time points (six-to-ten weeks after ADX) that in combination with CORT replacement, methods that increase neurogenesis in the normal animal continue to do so in the damaged dentate gyrus.

As in normal animals, we show that the stem-cell niche in the subgranular zone of chronic ADX rats can be modulated. Using a combination of exercise and environmental enrichment, we show that early stages of neurogenesis can be upregulated in the ADX rat. A 24-hour alternating regimen of wheel running and enriched environment exposure resulted in a significant increase in the number of migrating neuroblasts, as indicated by the microtubuleassociated protein DCX. This effect was similar to that which was observed in our controls, as well as to other reports of exercise-induced alterations in neurogenesis [66, 67]. Our observation provides further evidence of an intact neural stem-cell niche in the dentate gyrus of ADX rats. This upregulation of neurogenesis resulted in a significant increase in the volume of the dentate gyrus of ADX rats, relative to their home-cage ADX cohorts. Although at the sixweek time point the volume of the granule cell layer in treated ADX rats was still smaller than controls, the continuing high levels of DCX expression suggest that increasing the length of exposure to the combination of enrichment and exercise may suffice to restore the volume of the dentate gyrus granule cell layer to normal. The significant increase in dentate gyrus granule cell layer volume in the enriched ADX rats provides indirect evidence that adult born neurons survive in the damaged dentate gyrus.

We provide a method by which one form of intrinsic plasticity of the adult brain can be modulated in an attempt to induce functional recovery. Here, we employ behavioural and pharmacological techniques that increase the birth and survival of new neurons in the hippocampus. We show that repopulation of the damaged dentate gyrus via adultborn neurons is a viable approach to induce functional recovery. Treatment strategies employing transplantation of exogenous stem cells have proven to be relatively ineffective in alleviating function deficits [8-10]. A number of issues result from such methods, including the long-term survival of grafted cells and the inability to determine conclusively whether or not grafted cells functionally integrate into an existing neural network [6]. Here, we manipulate a naturally occurring system that continually results in the functional integration of new neurons into an existing network within the adult animal.

The functional integration of new neurons in the adult animal provides a treatment strategy by which an increase in the number of new cells results in a repopulation of a previously damaged brain region. The effectiveness of treatment methods designed to induce repopulation of the granule cell layer and induce functional recovery can be assessed using the available tools and techniques discussed in the preceding paper. Importantly, this demonstration of the loss of function associated with brain damage and the development of treatment strategies that result in functional recovery provides a model by which the required conditions for replacing neural circuitry in other brain regions may be explored.

\section{Acknowledgment}

The authors wish to acknowledge CIHR, AHFMR (AIHS), and the Heart and Stroke Foundation of Canada. 


\section{References}

[1] J. Götz and L. M. Ittner, "Animal models of Alzheimer's disease and frontotemporal dementia," Nature Reviews Neuroscience, vol. 9, no. 7, pp. 532-544, 2008.

[2] M. E. Smith, "Bilateral hippocampal volume reduction in adults with post-traumatic stress disorder: a meta-analysis of structural MRI studies," Hippocampus, vol. 15, no. 6, pp. 798 807, 2005.

[3] A. Brück, T. Kurki, V. Kaasinen, T. Vahlberg, and J. O. Rinne, "Hippocampal and prefrontal atrophy in patients with early non-demented Parkinson's disease is related to cognitive impairment," Journal of Neurology, Neurosurgery and Psychiatry, vol. 75, no. 10, pp. 1467-1469, 2004.

[4] W. H. Theodore, S. Bhatia, J. Hatta et al., "Hippocampal atrophy, epilepsy duration, and febrile seizures in patients with partial seizures," Neurology, vol. 52, no. 1, pp. 132-136, 1999.

[5] A. C. DeVries, R. J. Nelson, R. J. Traystman, and P. D. Hurn, "Cognitive and behavioral assessment in experimental stroke research: will it prove useful?" Neuroscience and Biobehavioral Reviews, vol. 25, no. 4, pp. 325-342, 2001.

[6] O. Lindvall and P. Hagell, "Role of cell therapy in Parkinson disease," Neurosurgical Focus, vol. 13, no. 5, p. e2, 2002.

[7] O. Lindvall and Z. Kokaia, "Prospects of stem cell therapy for replacing dopamine neurons in Parkinson's disease," Trends in Pharmacological Sciences, vol. 30, no. 5, pp. 260-267, 2009.

[8] H. Jeltsch, J. Yee, E. Aloy et al., "Transplantation of neurospheres after granule cell lesions in rats: cognitive improvements despite no long-term immunodetection of grafted cells," Behavioural Brain Research, vol. 143, no. 2, pp. 177-191, 2003.

[9] A. K. Shetty and D. A. Turner, "Development of fetal hippocampal grafts in intact and lesioned hippocampus," Progress in Neurobiology, vol. 50, no. 5-6, pp. 597-653, 1996.

[10] D. A. Turner, A. K. Shetty, B. Jacobs et al., "Clinical prospects for neural grafting therapy for hippocampal lesions and epilepsy," Neurosurgery, vol. 52, no. 3, pp. 632-644, 2003.

[11] B. Will, C. Kelche, and J. C. Cassel, "Intracerebral transplants and memory dysfunction: circuitry repair or functional level setting?" Neural Plasticity, vol. 7, no. 1-2, pp. 93-108, 2000.

[12] A. K. Shetty and B. Hattiangady, "Restoration of calbindin after fetal hippocampal CA3 cell grafting into the injured hippocampus in a rat model of temporal lobe epilepsy," Hippocampus, vol. 17, no. 10, pp. 943-956, 2007.

[13] C. Rüschenschmidt, P. G. Koch, O. Brüstle, and H. Beck, "Functional properties of ES cell-derived neurons engrafted into the hippocampus of adult normal and chronically epileptic rats," Epilepsia, vol. 46, no. 5, pp. 174-183, 2005.

[14] P. S. Eriksson, E. Perfilieva, T. Björk-Eriksson et al., "Neurogenesis in the adult human hippocampus," Nature Medicine, vol. 4, no. 11, pp. 1313-1317, 1998.

[15] R. S. Sloviter, G. Valiquette, G. M. Abrams et al., "Selective loss of hippocampal granule cells in the mature rat brain after adrenalectomy," Science, vol. 243, no. 4890, pp. 535-538, 1989.

[16] R. S. Sloviter, E. Dean, and S. Neubort, "Electron microscopic analysis of adrenalectomy-induced hippocampal granule cell degeneration in the rat: apoptosis in the adult central nervous system," Journal of Comparative Neurology, vol. 330, no. 3, pp. 337-351, 1993.

[17] E. Gould, C. S. Woolley, and B. S. McEwen, "Short-term glucocorticoid manipulations affect neuronal morphology and survival in the adult dentate gyrus," Neuroscience, vol. 37, no. 2, pp. 367-375, 1990.
[18] C. S. Woolley, E. Gould, R. R. Sakai, R. L. Spencer, and B. S. McEwen, "Effects of aldosterone or RU28362 treatment on adrenalectomy-induced cell death in the dentate gyrus of the adult rat," Brain Research, vol. 554, no. 1-2, pp. 312-315, 1991.

[19] D. Jaarsma, F. Postema, and J. Korf, "Time course and distribution of neuronal degeneration in the dentate gyrus of rat after adrenalectomy: a silver impregnation study," Hippocampus, vol. 2, no. 2, pp. 143-150, 1992.

[20] C. Park, M. Kang, Y. Kim-Kwon, J. Kim, H. Ahn, and Y. Huh, "Inhibition of neuronal nitric oxide synthase increases adrenalectomy-induced granule cell death in the rat dentate gyrus," Brain Research, vol. 933, no. 1, pp. 81-84, 2002.

[21] S. Andrés, S. Cárdenas, C. Parra et al., "Effects of long-term adrenalectomy on apoptosis and neuroprotection in the rat hippocampus," Endocrine, vol. 29, no. 2, pp. 299-307, 2006.

[22] M. Greiner, S. Cárdenas, C. Parra et al., "Adrenalectomy regulates apoptotic-associated genes in rat hippocampus," Endocrine, vol. 15, no. 3, pp. 323-333, 2001.

[23] L. C. Schmued and K. J. Hopkins, "Fluoro-Jade B: a high affinity fluorescent marker for the localization of neuronal degeneration," Brain Research, vol. 874, no. 2, pp. 123-130, 2000.

[24] M. Walker, D. Chan, and M. Thom, "Hippocampus and human disease," in The Hippocampus Book, P. Anderson, R. Morris, D. Amaral, T. Bliss, and J. O'Keefe, Eds., pp. 769-812, Oxford University Press, New York, NY, USA, 2007.

[25] C. K. Petito, E. Feldmann, W. A. Pulsinelli, and F. Plum, "Delayed hippocampal damage in humans following cardiorespiratory arrest," Neurology, vol. 37, no. 8, pp. 1281-1286, 1987.

[26] R. R. Hicks, D. H. Smith, D. H. Lowenstein, R. Saint Marie, and T. K. McIntosh, "Mild experimental brain injury in the rat induces cognitive deficits associated with regional neuronal loss in the hippocampus," Journal of Neurotrauma, vol. 10, no. 4, pp. 405-414, 1993.

[27] P. Kumar, H. Kalonia, and A. Kumar, "Huntington's disease: pathogenesis to animal models," Pharmacological Reports, vol. 62, no. 1, pp. 1-14, 2010.

[28] A. J. Lees, J. Hardy, and T. Revesz, "Parkinson's disease," The Lancet, vol. 373, no. 9680, pp. 2055-2066, 2009.

[29] S. C. Spanswick and R. J. Sutherland, "Object/context-specific memory deficits associated with loss of hippocampal granule cells after adrenalectomy in rats," Learning \& Memory, vol. 17, no. 5, pp. 241-245, 2010.

[30] M. J. West, G. Danscher, and H. Gydesen, "A determination of the volumes of the layers of the rat hippocampal region," Cell and Tissue Research, vol. 188, no. 3, pp. 345-359, 1978.

[31] M. J. West, L. Slomianka, and H. J. G. Gundersen, "Unbiased stereological estimation of the total number of neurons in the subdivisions of the rat hippocampus using the optical fractionator," Anatomical Record, vol. 231, no. 4, pp. 482-497, 1991.

[32] P. R. Mouton, Principles and Practices of Unbiased Stereology: An Introduction for Bioscientists, The Johns Hopkins University Press, Baltimore, Md, USA, 2002.

[33] C. Schmitz and P. R. Hof, "Design-based stereology in neuroscience," Neuroscience, vol. 130, no. 4, pp. 813-831, 2005.

[34] J. N. Armstrong, D. C. McIntyre, S. Neubort, and R. S. Sloviter, "Learning and memory after adrenalectomy-induced hippocampal dentate granule cell degeneration in the rat," Hippocampus, vol. 3, no. 3, pp. 359-371, 1993.

[35] B. Roozendaal, R. M. Sapolsky, and J. L. McGaugh, "Basolateral amygdala lesions block the disruptive effects of long-term 
adrenalectomy on spatial memory," Neuroscience, vol. 84, no. 2, pp. 453-465, 1998.

[36] S. C. Spanswick, J. R. Epp, J. R. Keith, and R. J. Sutherland, "Adrenalectomy-induced granule cell degeneration in the hippocampus causes spatial memory deficits that are not reversed by chronic treatment with corticosterone or fluoxetine," Hippocampus, vol. 17, no. 2, pp. 137-146, 2007.

[37] C. M. Stienstra, F. van der Graaf, A. Bosma, Y. J. G. Karten, W. Hesen, and M. Joëls, "Synaptic transmission in the rat dentate gyrus after adrenalectomy," Neuroscience, vol. 85, no. 4, pp. 1061-1071, 1998.

[38] J. Wossink, H. Karst, O. Mayboroda, and M. Joëls, "Morphological and functional properties of rat dentate granule cells after adrenalectomy," Neuroscience, vol. 108, no. 2, pp. 263 272, 2001.

[39] H. J. Krugers, S. van der Linden, E. van Olst et al., "Dissociation between apoptosis, neurogenesis, and synaptic potentiation in the dentate gyrus of adrenalectomized rats," Synapse, vol. 61, no. 4, pp. 221-230, 2007.

[40] D. G. Margineanu, A. J. Gower, J. Gobert, and E. Wulfert, "Long-term adrenalectomy reduces hippocampal granule cell excitability in vivo," Brain Research Bulletin, vol. 33, no. 1, pp. 93-98, 1993.

[41] R. J. Sutherland, I. Q. Whishaw, and B. Kolb, "A behavioural analysis of spatial localization following electrolytic, kainateor colchicine-induced damage to the hippocampal formation in the rat," Behavioural Brain Research, vol. 7, no. 2, pp. 133153,1983

[42] G. F. Xavier, F. J. B. Oliveira-Filho, and A. M. G. Santos, "Dentate gyrus-selective colchicine lesion and disruption of performance in spatial tasks: difficulties in 'place strategy' because of a lack of flexibility in the use of environmental cues?" Hippocampus, vol. 9, no. 6, pp. 668-681, 1999.

[43] C. M. McCormick, M. McNamara, S. Mukhopadhyay, and J. E. Kelsey, "Acute corticosterone replacement reinstates performance on spatial and nonspatial memory tasks 3 months after adrenalectomy despite degeneration in the dentate gyrus," Behavioral Neuroscience, vol. 111, no. 3, pp. 518-531, 1997.

[44] N. O'Brien, H. Lehmann, V. Lecluse, and D. G. Mumby, "Enhanced context-dependency of object recognition in rats with hippocampal lesions," Behavioural Brain Research, vol. 170, no. 1, pp. 156-162, 2006.

[45] D. G. Mumby, S. Gaskin, M. J. Glenn, T. E. Schramek, and H. Lehmann, "Hippocampal damage and exploratory preferences in rats: memory for objects, places, and contexts," Learning \& Memory, vol. 9, no. 2, pp. 49-57, 2002.

[46] L. de Toledo-Morrell, B. Dickerson, M. P. Sullivan, C. Spanovic, R. Wilson, and D. A. Bennett, "Hemispheric differences in hippocampal volume predict verbal and spatial memory performance in patients with Alzheimer's disease," Hippocampus, vol. 10, no. 2, pp. 136-142, 2000.

[47] R. S. Astur, L. B. Taylor, A. N. Mamelak, L. Philpott, and R. J. Sutherland, "Humans with hippocampus damage display severe spatial memory impairments in a virtual Morris water task," Behavioural Brain Research, vol. 132, no. 1, pp. 77-84, 2002.

[48] A. Marschner, R. Kalisch, B. Vervliet, D. Vansteenwegen, and C. Büchel, "Dissociable roles for the hippocampus and the amygdala in human cued versus context fear conditioning," Journal of Neuroscience, vol. 28, no. 36, pp. 9030-9036, 2008.

[49] O. Pascalis, N. M. Hunkin, J. Bachevalier, and A. R. Mayes, "Change in background context disrupts performance on visual paired comparison following hippocampal damage," Neuropsychologia, vol. 47, no. 10, pp. 2107-2113, 2009.
[50] J. Laczó, R. Andel, M. Vyhnalek et al., "Human analogue of the morris water maze for testing subjects at risk of Alzheimer's Disease," Neurodegenerative Diseases, vol. 7, no. 1-3, pp. 148$152,2010$.

[51] G. Kempermann, S. Jessberger, B. Steiner, and G. Kronenberg, "Milestones of neuronal development in the adult hippocampus," Trends in Neurosciences, vol. 27, no. 8, pp. 447-452, 2004.

[52] A. Alvarez-Buylla and J. M. García-Verdugo, "Neurogenesis in adult subventricular zone," Journal of Neuroscience, vol. 22, no. 3, pp. 629-634, 2002.

[53] J. E. Malberg, A. J. Eisch, E. J. Nestler, and R. S. Duman, "Chronic antidepressant treatment increases neurogenesis in adult rat hippocampus," Journal of Neuroscience, vol. 20, no. 24, pp. 9104-9110, 2000.

[54] L. Santarelli, M. Saxe, C. Gross et al., "Requirement of hippocampal neurogenesis for the behavioral effects of antidepressants," Science, vol. 301, no. 5634, pp. 805-809, 2003.

[55] H. G. Kuhn, J. Winkler, G. Kempermann, L. J. Thal, and F. H. Gage, "Epidermal growth factor and fibroblast growth factor2 have different effects on neural progenitors in the adult rat brain," Journal of Neuroscience, vol. 17, no. 15, pp. 5820-5829, 1997.

[56] G. Kempermann, H. G. Kuhn, and F. H. Gage, "More hippocampal neurons in adult mice living in an enriched environment," Nature, vol. 386, no. 6624, pp. 493-495, 1997.

[57] A. K. Olson, B. D. Eadie, C. Ernst, and B. R. Christie, "Environmental enrichment and voluntary exercise massively increase neurogenesis in the adult hippocampus via dissociable pathways," Hippocampus, vol. 16, no. 3, pp. 250-260, 2006.

[58] J. Brown, C. M. Cooper-Kuhn, G. Kempermann et al., "Enriched environment and physical activity stimulate hippocampal but not olfactory bulb neurogenesis," European Journal of Neuroscience, vol. 17, no. 10, pp. 2042-2046, 2003.

[59] E. Gould, H. A. Cameron, D. C. Daniels, C. S. Woolley, and B. S. McEwen, "Adrenal hormones suppress cell division in the adult rat dentate gyrus," Journal of Neuroscience, vol. 12, no. 9 , pp. 3642-3650, 1992.

[60] H. A. Cameron, "Adult neurogenesis is regulated by adrenal steroids in the dentate gyrus," Neuroscience, vol. 61, no. 2, pp. 203-209, 1994.

[61] P. Tanapat, N. B. Hastings, T. A. Rydel, L. A. M. Galea, and E. Gould, "Exposure to fox odor inhibits cell proliferation in the hippocampus of adult rats via an adrenal hormone-dependent mechanism," Journal of Comparative Neurology, vol. 437, no. 4, pp. 496-504, 2001.

[62] M. F. Montaron, K. G. Petry, J. J. Rodriguez et al., "Adrenalectomy increases neurogenesis but not PSA-NCAM expression in aged dentate gyrus," European Journal of Neuroscience, vol. 11, no. 4, pp. 1479-1485, 1999.

[63] E. Y. H. Wong and J. Herbert, "Roles of mineralocorticoid and glucocorticoid receptors in the regulation of progenitor proliferation in the adult hippocampus," European Journal of Neuroscience, vol. 22, no. 4, pp. 785-792, 2005.

[64] A. Tashiro, H. Makino, and F. H. Gage, "Experience-specific functional modification of the dentate gyrus through adult neurogenesis: a critical period during an immature stage," Journal of Neuroscience, vol. 27, no. 12, pp. 3252-3259, 2007.

[65] R. Auvergne, C. Leré, B. El Bahh et al., "Delayed kindling epileptogenesis and increased neurogenesis in adult rats housed in an enriched environment," Brain Research, vol. 954, no. 2, pp. 277-285, 2002.

[66] H. van Praag, B. R. Christie, T. J. Sejnowski, and F. H. Gage, "Running enhances neurogenesis, learning, and long-term potentiation in mice," Proceedings of the National Academy of 
Sciences of the United States of America, vol. 96, no. 23, pp. 13427-13431, 1999.

[67] J. S. Rhodes, S. Jeffrey, I. Girard et al., "Exercise increases hippocampal neurogenesis to high levels but does not improve spatial learning in mice bred for increased voluntary wheel running," Behavioral Neuroscience, vol. 117, no. 5, pp. 10061016, 2003.

[68] A. S. Naylor, A. I. Persson, P. S. Eriksson, I. H. Jonsdottir, and T. Thorlin, "Extended voluntary running inhibits exerciseinduced adult hippocampal progenitor proliferation in the spontaneously hypertensive rat," Journal of Neurophysiology, vol. 93, no. 5, pp. 2406-2414, 2005.

[69] G. Kempermann and F. H. Gage, "Experience-dependent regulation of adult hippocampal neurogenesis: effects of longterm stimulation and stimulus withdrawal," Hippocampus, vol. 9, no. 3, pp. 321-332, 1999.

[70] G. Lai, H. Lehmann, S. C. Spanswick, H. Yamazaki, and R. J. Sutherland, "Behavior deficit and functional recovery after granule cell death in the hippocampus," Society for Neuroscience Abstracts, p. 779.8, 2007.

[71] K. S. Rai, B. Hattiangady, and A. K. Shetty, "Enhanced production and dendritic growth of new dentate granule cells in the middle-aged hippocampus following intracerebroventricular FGF-2 infusions," European Journal of Neuroscience, vol. 26, no. 7, pp. 1765-1779, 2007.

[72] S. Ahn and A. L. Joyner, "In vivo analysis of quiescent adult neural stem cells responding to Sonic hedgehog," Nature, vol. 437, no. 7060, pp. 894-897, 2005.

[73] V. Palam, D. A. Lim, N. Dahmane et al., "Sonic hedgehog controls stem cells behavior in the postnatal and adult brain," Development, vol. 132, no. 2, pp. 335-344, 2005.

[74] R. R. Hicks, D. H. Smith, D. H. Lowenstein, R. Saint Marie, and T. K. McIntosh, "Mild experimental brain injury in the rat induces cognitive deficits associated with regional neuronal loss in the hippocampus," Journal of Neurotrauma, vol. 10, no. 4, pp. 405-414, 1993.

[75] T. Yamaki, N. Murakami, Y. Iwamoto et al., "Cognitive dysfunction and histological findings in rats with chronicstage contusion and diffuse axonal injury," Brain Research Protocols, vol. 3, no. 1, pp. 100-106, 1998.

[76] J. W. Huh and R. Raghupathi, "Chronic cognitive deficits and long-term histopathological alterations following contusive brain injury in the immature rat," Journal of Neurotrauma, vol. 24, no. 9, pp. 1460-1474, 2007.

[77] K. D. Langdon, S. Granter-Button, and D. Corbett, "Persistent behavioral impairments and neuroinflammation following global ischemia in the rat," European Journal of Neuroscience, vol. 28, no. 11, pp. 2310-2318, 2008. 


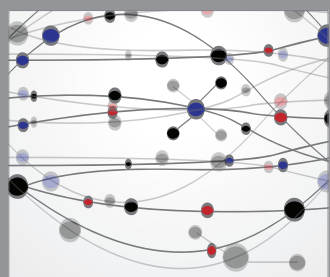

The Scientific World Journal
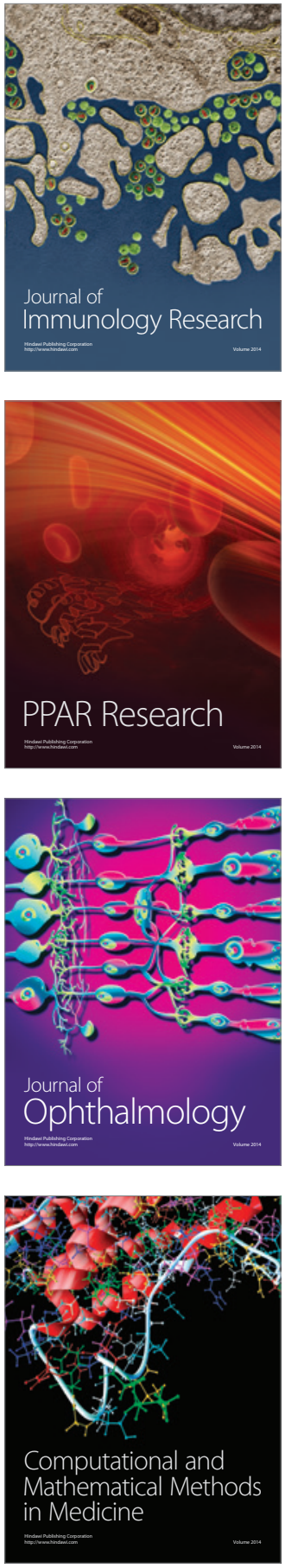

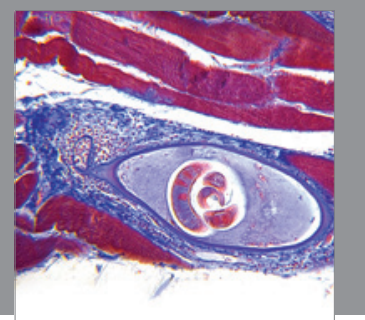

Gastroenterology

Research and Practice
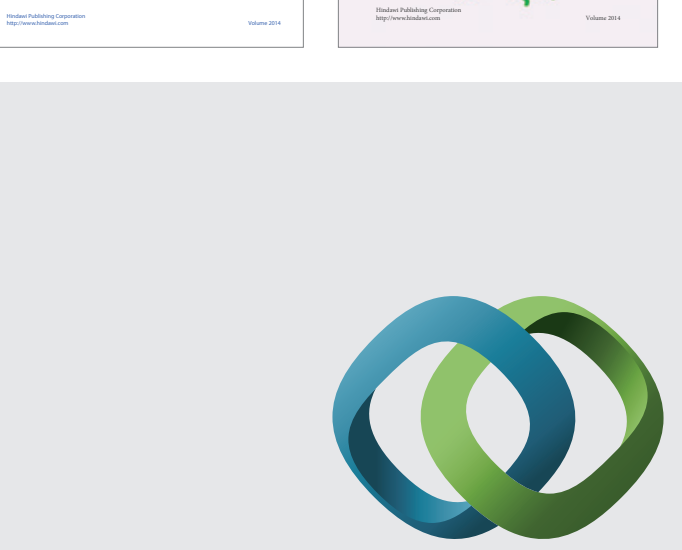

\section{Hindawi}

Submit your manuscripts at

http://www.hindawi.com
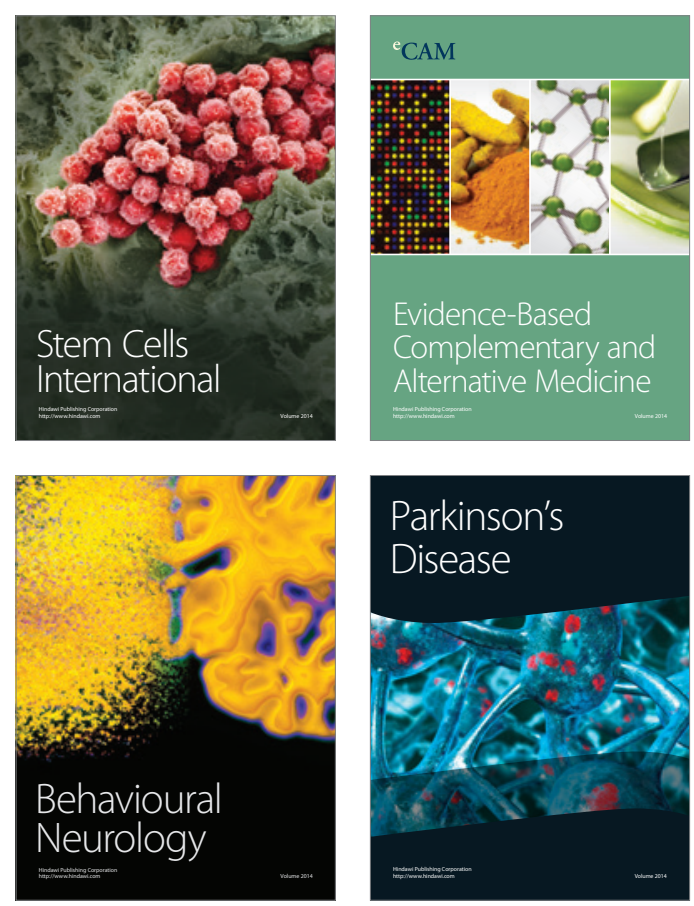

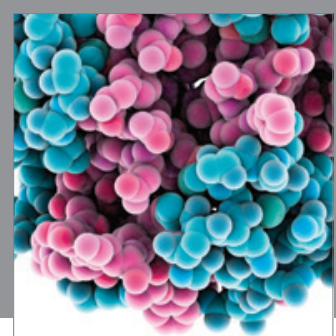

Journal of
Diabetes Research

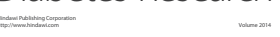

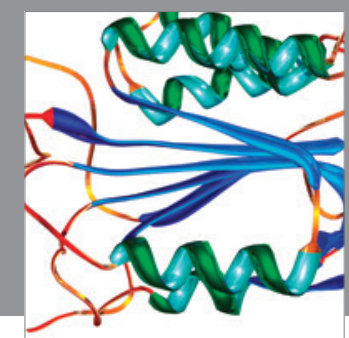

Disease Markers
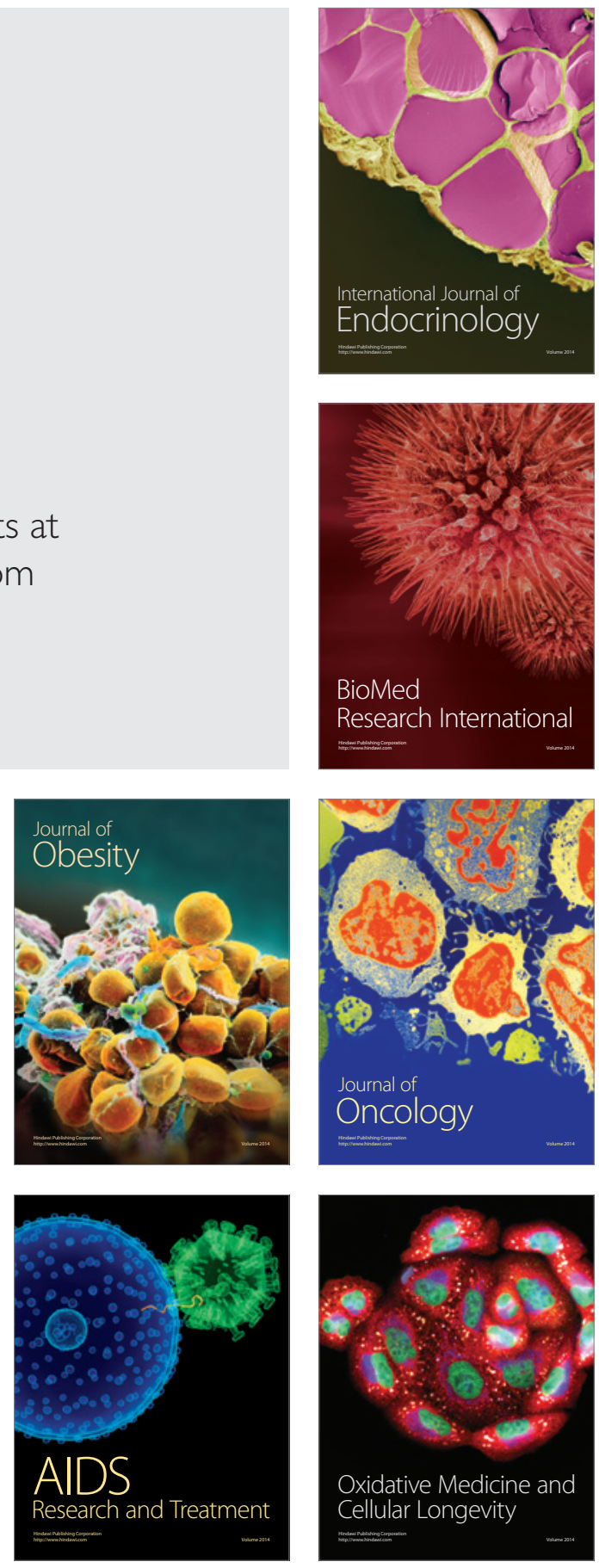